\title{
Comparative efficacy of sodium-glucose cotransporter-2 inhibitors (SGLT2i) for cardiovascular outcomes in type 2 diabetes: a systematic review and network meta-analysis of randomised controlled trials
}

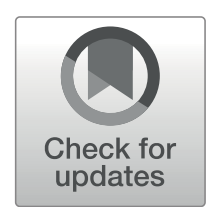

\author{
Tobias Täger $^{1}$ - Dan Atar ${ }^{2} \cdot$ Stefan Agewall ${ }^{2}$ Hugo A. Katus ${ }^{1}$. Morten Grundtvig ${ }^{3} \cdot$ John G. F. Cleland $^{4}$. \\ Andrew L. Clark ${ }^{5} \cdot$ Hanna Fröhlich ${ }^{1} \cdot$ Lutz Frankenstein ${ }^{1}$
}

Published online: 20 April 2020

(C) The Author(s) 2020

\begin{abstract}
Sodium-glucose cotransporter-2 inhibitors (SGLT2i) improve cardiovascular outcomes in patients with type 2 diabetes mellitus (T2D). The comparative efficacy of individual SGLT2i remains unclear. We searched PubMed, www.clinicaltrials.gov and the Cochrane Central Register of Controlled Trials for randomised controlled trials exploring the use of canagliflozin, dapagliflozin, empagliflozin or ertugliflozin in patients with T2D. Comparators included placebo or any other active treatment. The primary endpoint was all-cause mortality. Secondary endpoints were cardiovascular mortality and worsening heart failure (HF). Evidence was synthesised using network meta-analysis (NMA). Sixty-four trials reporting on 74,874 patients were included. The overall quality of evidence was high. When compared with placebo, empagliflozin and canagliflozin improved all three endpoints, whereas dapagliflozin improved worsening HF. When compared with other SGLT2i, empagliflozin was superior for all-cause and cardiovascular mortality reduction. Empagliflozin, canagliflozin and dapagliflozin had similar effects on improving worsening HF. Ertugliflozin had no effect on any of the three endpoints investigated. Sensitivity analyses including extension periods of trials or excluding studies with a treatment duration of $<52$ weeks confirmed the main results. Similar results were obtained when restricting mortality analyses to patients included in cardiovascular outcome trials $(n=38,719)$. Empagliflozin and canagliflozin improved survival with empagliflozin being superior to the other SGLT2i. Empagliflozin, canagliflozin and dapagliflozin had similar effects on improving worsening HF. Prospective head-to-head comparisons would be needed to confirm these results.
\end{abstract}

Keywords Sodium-glucose cotransporter-2 inhibitors · Type 2 diabetes $\cdot$ Mortality $\cdot$ Heart failure $\cdot$ Efficacy

Hanna Fröhlich and Lutz Frankenstein shared last authorship

Electronic supplementary material The online version of this article (https://doi.org/10.1007/s10741-020-09954-8) contains supplementary material, which is available to authorized users.

Lutz Frankenstein

lutz.frankenstein@med.uni-heidelberg.de

1 Department of Cardiology, Angiology, and Pulmonology, University Hospital Heidelberg, Im Neuenheimer Feld 410, 69120 Heidelberg, Germany

2 Department of Cardiology, Oslo University Hospital, Ulleval and Institute of Clinical Sciences, University of Oslo, Oslo, Norway

3 Medical Department, Innlandet Hospital Trust Division Lillehammer, Lillehammer, Norway

$4 \quad$ National Heart \& Lung Institute, Royal Brompton \& Harefield Hospitals, Imperial College, London, and Robertson Centre for Biostatistics \& Clinical Trials, Glasgow, UK

5 Castle Hill Hospital of the University of Hull, Cottingham, UK

\section{Introduction}

Sodium-glucose cotransporter-2 inhibitors (SGLT2i) are a new class of oral anti-diabetic drugs (OAD) with a moderate effect on glycaemic control and a low risk of hypoglycaemia and weight gain $[1,2]$. Current evidence suggests that SGLT2i improve cardiovascular endpoints including all-cause mortality, cardiovascular mortality, heart failure (HF) and atherosclerotic macrovascular events [3]. The magnitude of cardiovascular risk reduction with SGLT2i, however, differed between trials [3-6]. Furthermore, there is concern regarding the potential cardiovascular safety of some OAD [7]. There is thus remaining uncertainty about the comparative efficacy of individual SGLT2i or whether a class effect can be assumed. To date, there are no prospective or retrospective head-to-head comparisons of individual SGLT2i. Given the required sample size and associated costs, a comparative SGLT2i trial may never be done. We therefore performed a network meta- 
analysis (NMA) of randomised controlled trials to compare comprehensively the cardiovascular benefits of SGLT2i in patients with type 2 diabetes mellitus (T2D).

\section{Methods}

NMA is an extension of pairwise meta-analysis in which multiple treatments are being compared using both direct comparisons of interventions within randomised controlled trials and indirect comparisons across trials based on a common comparator. NMA has advantages over pairwise meta-analysis, such as clarification of inconsistent outcomes from multiple studies including multiple common comparators and indirect effect calculation of missing direct comparisons between important treatments. Also, NMA can provide increased statistical power and cross-validation of the observed treatment effect of weak connections with reasonable network connectivity and sufficient sample sizes. This results in greater precision of treatment effect estimates and the ability to rank all the interventions in a coherent way.

We performed the present review following the Preferred Reporting Items for Systematic Reviews and Meta-Analyses (PRISMA) extension statement for reporting systematic reviews incorporating NMAs of health care interventions [8-11]. The protocol of the NMA was prospectively registered at final registration ID at PROSPERO: CRD42020151112.

\section{Identification and selection of studies}

We searched electronic databases (PubMed, Cochrane Central Register of Controlled Trials) and websites (www. clinicaltrials.gov) up to August 12, 2019 for randomised controlled trials investigating the use of canagliflozin, dapagliflozin, empagliflozin or ertugliflozin in patients with T2D. Details of the search strategy are provided in the supplemental material. In addition, reviews and metaanalyses of SGLT2i published in PubMed between 2017 and 2019 were screened for additional SGLT2i trials. Two reviewers independently screened citations against the following predefined selection criteria.

Study design Prospective randomised controlled trials with either parallel-group (all endpoints) or cross-over design (worsening heart failure (HF) only) were included. There were no restrictions regarding date of publication, language or sample size.

Population We included studies evaluating adults $(\geq 18$ years) with a diagnosis of T2D and treatment with SGLT2i for at least 24 weeks. There were no restrictions regarding sex, race, background diabetes treatment or dose of SGLT2i.
Interventions Treatment was with either canagliflozin, dapagliflozin, empagliflozin or ertugliflozin for at least 24 weeks. This arbitrary limit of 24 weeks was chosen to allow a potential survival benefit to become detectable against the overall low short-term baseline mortality in diabetic cohorts. Analyses were restricted to canagliflozin, dapagliflozin, empagliflozin and ertugliflozin since these agents have been approved by both the United States Food and Drug Administration and the European Medicines Agency.

Comparators Placebo or standard medical care.

Outcomes Primary outcome was all-cause mortality. Secondary outcomes included cardiovascular mortality and worsening HF.

\section{Data extraction and quality assessment}

All relevant articles were independently reviewed by two investigators to assess the eligibility of the article and abstract with standardised data abstraction forms, and disagreement was resolved by a third investigator. For each trial included, details were extracted on study design, patient characteristics, interventions and outcomes. The quality of included trials was assessed using the Cochrane Collaboration Criteria [12].

\section{Statistical analyses}

This NMA was conducted with Stata software 15.0 (StataCorp, College Station, TX, USA) using the network family of commands $[13,14]$. A random effects model was applied. The NMA was performed to obtain estimates for outcomes of primary and secondary endpoints, presented as relative risks (RR) and 95\% confidence intervals (CI) for binary outcomes. The plot of a network of drugs was used as a visual representation of the evidence base and offered a concise description of its characteristics. It consists of nodes representing the drugs being compared and edges representing the available direct comparisons (comparisons evaluated in at least one study) between pairs of drugs [14-16]. The quality of treatment effect estimates was rated following the Grading of Recommendations Assessment, Development and Evaluation (GRADE) approach [17, 18]. In order to make the rank of treatments, we used the surface under the cumulative ranking probabilities (SUCRA) - a transformation of the mean rank that accounts both for the location and the variance of all relative treatment effects [19]. SUCRA values range from 0 to 1.0. The higher the SUCRA value, and the closer to 1.0, the higher the likelihood that a therapy is in the top rank or one of the top ranks; the closer to 0 the SUCRA value, the more likely that a therapy is in the bottom rank, or one of the bottom ranks [20]. To check for a publication bias, we designed a funnel plot [14]. Consistency of results was evaluated 
Fig. 1 Network plots with respect to a all-cause mortality, b cardiovascular mortality, and $\mathbf{c}$ worsening HF. Legend: CANA, canagliflozin; DAPA, dapagliflozin; EMPA, empagliflozin; ERTU, ertugliflozin; EXE, exenatide; GLIME, glimepiride; GLIP, glipizide; LINA, linagliptin; MET, metformin; PLA, placebo; SAXA, saxagliptin; SITA, sitagliptin; VILDA, vildagliptin. Nodes represent the interventions of interest and edges represent available direct comparisons between pairs of interventions. Nodes and edges are weighted according to the number of studies including the respective interventions. Coloured edges are employed to present the risk of bias for each direct comparison in the network, with green, yellow and red colours being used to denote pairwise metaanalyses of low, unclear and high risk of bias

in each loop by calculation of an inconsistency factor and statistical significance determined via z-test $[16,21]$.

For trials comprising a core period and an extension period, results of the core period were considered in the main analyses. To test the stability of the results, we performed a sensitivity analysis by including the results of the extension periods of the respective trials, provided that double-blind treatment was continued unchanged during the extension period. If treatment changed during the extension period of a trial, only results from the core period were considered. Additional sensitivity analyses excluded studies with a high risk of bias, studies with a treatment duration $<52$ weeks and those not designed as cardiovascular outcome trials. Data on different dosages of active treatments and/or comparators were pooled for each study. Study arms including more than one active treatment (= combination therapy) were excluded from endpoint analyses. All $p$ values were two-tailed with the statistical significance arbitrarily set at $<0.05$.

\section{Results}

\section{Literature search}

The search strategy yielded 73 eligible records reporting on 64 trials [4-6, 22-87]. For three trials (NCT02681094, NCT02630706, NCT00736879), results were not published in a peer-reviewed journal but open to public at www. clinicaltrials.gov. Information on study design and results were thus extracted from www.clinicaltrials.gov. The flowchart of the study selection process is shown in eFig. 1 . Agreement between reviewers was excellent $(\kappa=0.935,95 \%$ CI 0.891-0.980).

No trials directly compared two different SGLT2i. A total of 44 trials compared SGLT2i with placebo, and 18 trials compared SGLT2i with other active treatments. Two trials compared SGLT2 $i$ with both placebo and another active treatment. Canagliflozin was studied in 14 trials $(n=22,220$ patients), whereas dapagliflozin was studied in 30 trials $(n=$ 31,863 patients). Thirteen trials including 15,716 patients investigated the use of empagliflozin, and seven trials studied
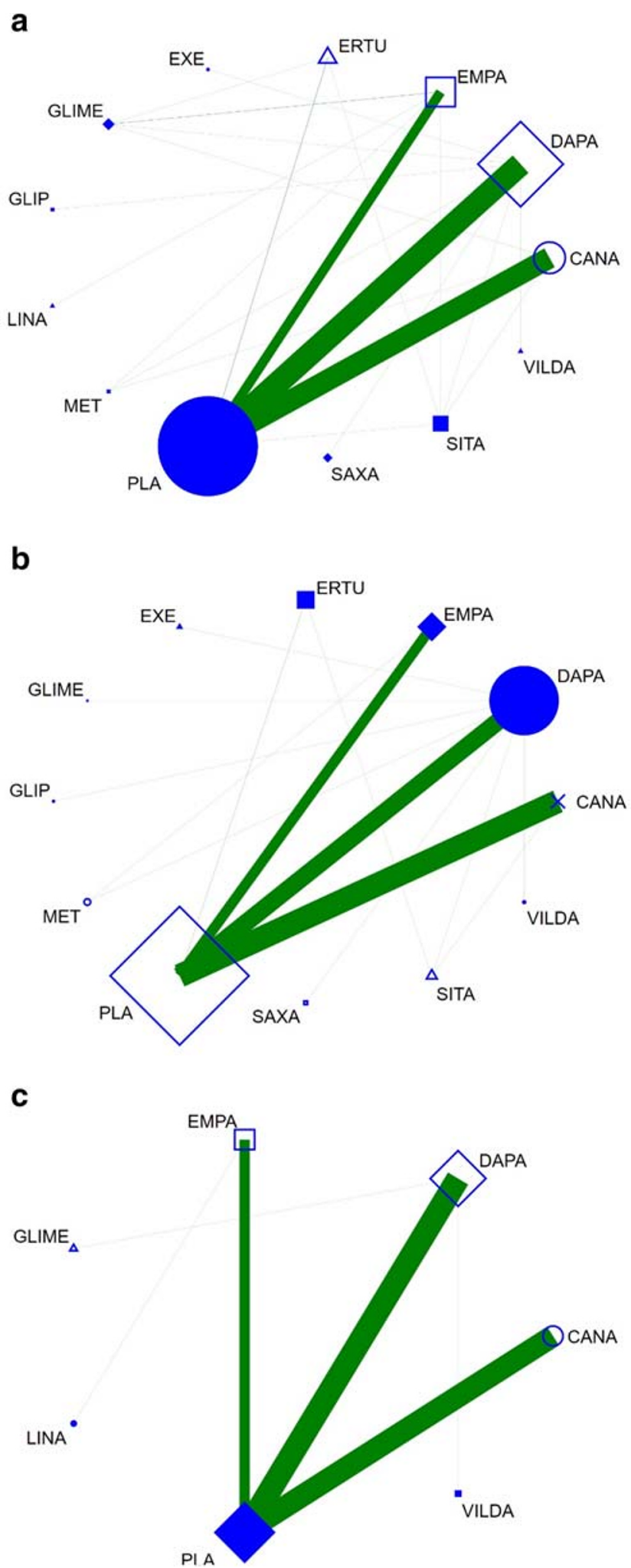

ertugliflozin ( $n=5074$ patients). The corresponding network plots detailing active treatments and endpoints reported are shown in Fig. 1a-c. All but one were multicentre, parallelgroup trials and the mean treatment duration of the core trials was 40 weeks. Fifteen trials comprised a core period and an 
extension period, in which double-blind treatment was continued unchanged. The mean study duration including extension periods was 52 weeks. In total, the 64 trials reported data from 74,874 patients. Of these, 3155 patients were randomised to a combination treatment of more than one study drug and were therefore excluded from endpoint analyses. Outcome data were thus analysed from 71,719 patients. For study characteristics of trials included in the present NMA, please refer to Table 1.

\section{Patient characteristics}

Patients were on average between 52 and 69 years old and baseline HbA1c varied between $7.2 \%$ and $9.3 \%$. The majority of patients had preserved renal function. The prevalence of cardiovascular disease was reported in 15 trials and varied between $26.1 \%$ and $100 \%$, totalling 26,360 patients. A total of 7534 patients from 14 trials was treatment-naïve, whereas 67,340 patients received background treatment for diabetes with OADs and/or insulin. For details, please see eTable 1.

\section{Risk of bias}

The overall risk of bias was low. With respect to the individual items of the risk of bias assessment (eFig. 2), the majority of studies provided adequate random sequence generation with good group balance at baseline. All-cause mortality could be retrieved for all but one trial, whereas cardiovascular mortality was reported in $46(71.9 \%)$ trials ( $n=59,168$ patients). Data on HF outcomes were available for 42,683 patients included in 12 trials. There was no systematic association between type or size of the trial or the publication date and any pattern of missing endpoint information. The comparison adjusted funnel plot for all-cause mortality (eFig. 3) was symmetrical, suggesting the absence of small-study effects and publication bias.

\section{Outcomes}

For all endpoints including the respective outcome numbers per trial arm, please refer to eTable 2 .

\section{All-cause mortality}

The predictive interval plot summarizing the relative mean effects along with the impact of heterogeneity on the respective confidence interval (= the predictive interval) of each (network) comparison is shown in Fig. 2. Canagliflozin, dapagliflozin and empagliflozin all had a beneficial effect on all-cause mortality compared with placebo. In head-to-head comparisons, the analysis suggests that empagliflozin is superior to both canagliflozin and dapagliflozin. No other head-tohead comparison of any pair of treatments (including non-
SGLT2 treatments) found a significant difference between agents, though for most of these comparisons, the $95 \% \mathrm{CI}$ was wide. SUCRA values are presented in Table 2. The graphical display of the ranking based on the SUCRA values is shown in eFig. 4. The inconsistency within the respective closed loops for each comparison was overall low (eFig. 5) and did not reach statistical significance for any of the loops.

\section{Cardiovascular mortality}

The predictive interval plot (Fig. 3) showed that empagliflozin was again superior to placebo, canagliflozin and dapagliflozin in reducing cardiovascular mortality. Canagliflozin also reduced cardiovascular mortality compared with placebo. No other head-to-head comparison of any pair of treatments (including non-SGLT2 treatments) found a significant difference between agents, though again for most of these comparisons, the $95 \%$ CI was wide. SUCRA values are presented in Table 2. The graphical display of the ranking based on the SUCRA values is shown in eFig. 6. The inconsistency within the respective closed loops for each comparison was overall low (eFig. 7) and again did not reach statistical significance for any of the loops.

\section{Worsening HF}

The predictive interval plot (Fig. 4) showed that canagliflozin, dapagliflozin and empagliflozin all reduced the endpoint of worsening HF when compared with placebo. There were no further significant differences in $\mathrm{HF}$ outcomes between individual SGLT2i. SUCRA values are presented in Table 2. The graphical display of the ranking based on the SUCRA values is shown in eFig. 8. No closed loops were formed and consequently no inconsistency could be derived.

\section{Sensitivity analyses}

Sensitivity analyses essentially confirmed our main results. When we included the results of study extension periods to the outcome analyses, empagliflozin was again more effective in reducing all-cause and cardiovascular mortality than all other agents, while there was no difference between the individual SGLT2 $\mathrm{i}$ in reducing worsening HF (eFig. 9, 10 and 11). Results were similar after excluding trials with a treatment duration $<52$ weeks (eFig. 12, 13 and 14) or when restricting our analyses to patients included in cardiovascular outcome trials ( $n=38,719$; eFig. 15,16 and 17 ). As we did not identify any trials with a high risk of bias, the corresponding sensitivity analysis was not appropriate. 


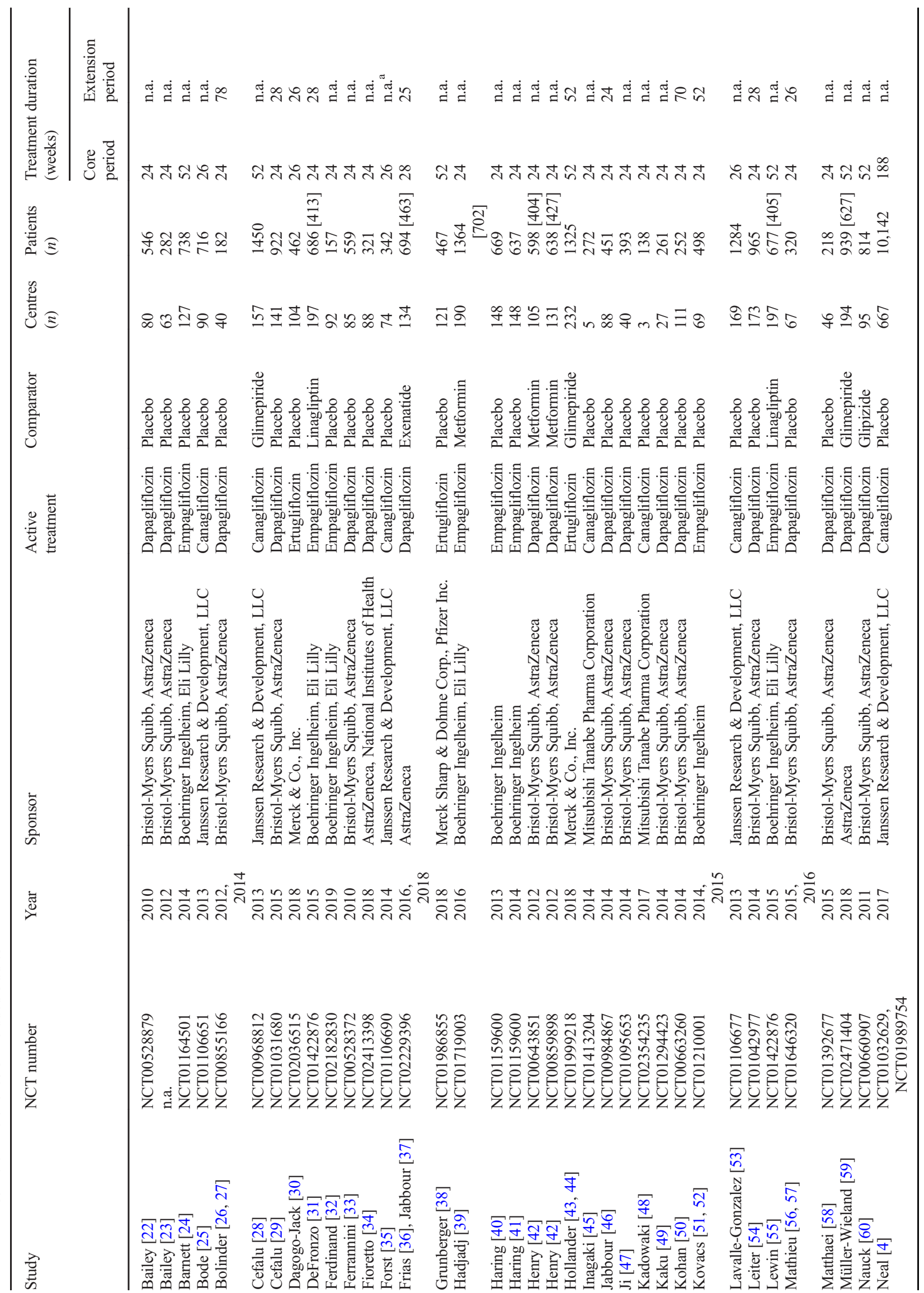




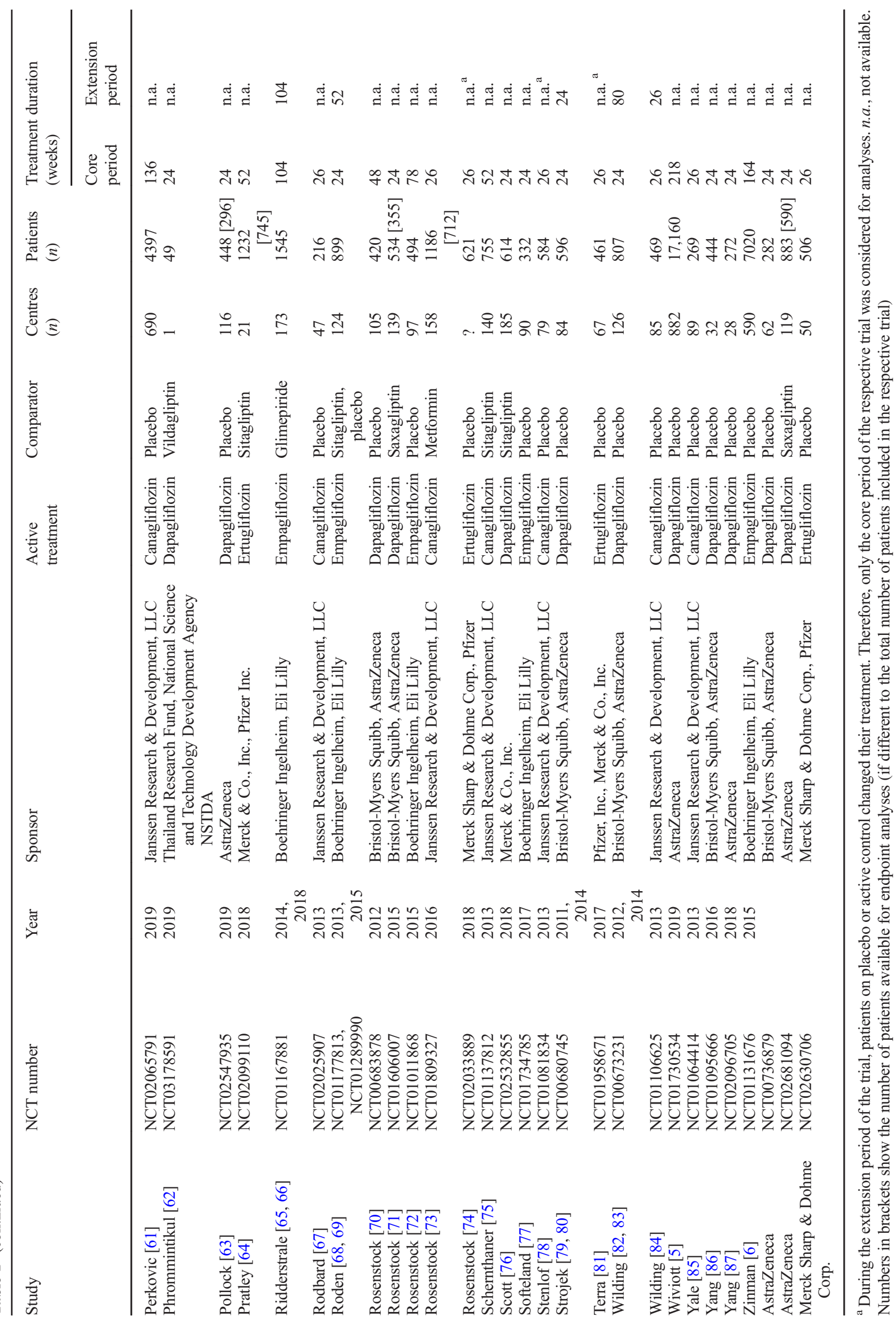


Fig. 2 Predictive interval plot for all-cause mortality. Legend: The predictive interval plot represents a forest plot of the joint estimated summary effects from both direct and indirect comparisons along with their confidence intervals. Significant results are shown in read colour

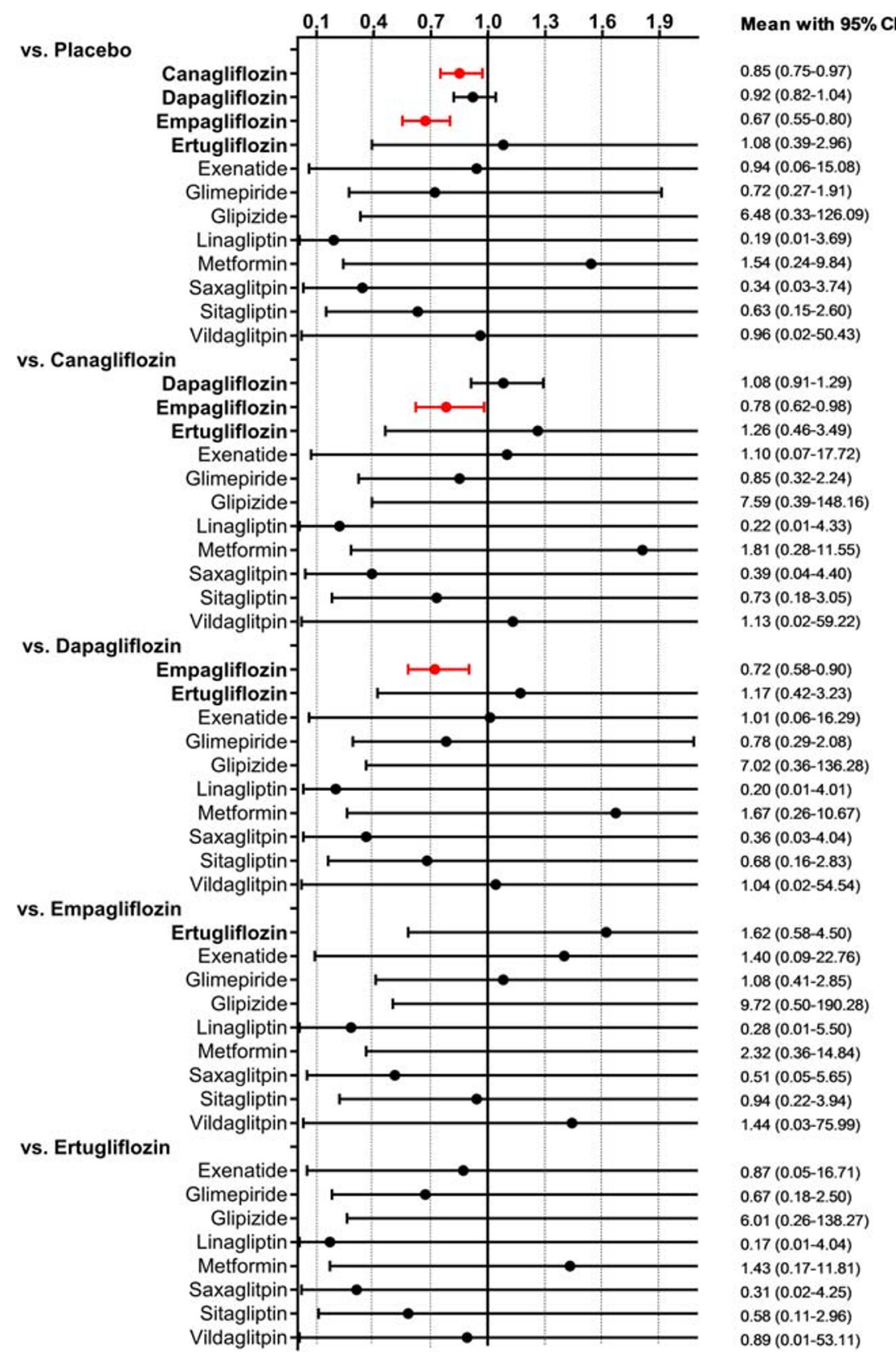

\section{Discussion}

SGLT2i belong to a new class of OAD that confer benefits on cardiovascular endpoints in patients with T2D. To date, there is no randomised controlled trial (RCT) or retrospective headto-head comparison of any available SGLT2i. NMA is an increasingly popular tool for comparative effectiveness research. The integration of direct (head-to-head) and indirect (transitively derived via a common comparator) evidence allows for comparisons that otherwise elude conventional (aggregate) analysis while increasing precision in the estimates along the way. The present analysis is thus the first to provide evidence of the comparative cardiovascular effects of different SGLT2i in patients with T2D.

In a comprehensive analysis of almost 75,000 patients derived from 64 trials, we found that while empagliflozin, canagliflozin and dapagliflozin reduce all-cause mortality compared with placebo, empagliflozin appears more effective than the latter two. These results were essentially mirrored for cardiovascular mortality, while all three appear of similar efficacy with respect to worsening HF. Ertugliflozin had no effect on any of the three endpoints investigated.

The mortality advantage of empagliflozin reflects the results of four recently published large-scale placebo-controlled 
Table 2 Surface under the cumulative ranking curve (SUCRA) values for all endpoints

\begin{tabular}{llll}
\hline SUCRA & All-cause mortality & Cardiovascular mortality & Worsening HF \\
\hline Canagliflozin & 0.519 & 0.533 & 0.754 \\
Dapagliflozin & 0.437 & 0.414 & 0.537 \\
Empagliflozin & 0.684 & 0.697 & 0.677 \\
Ertugliflozin & 0.385 & 0.659 & n.a. \\
Placebo & 0.335 & 0.374 & 0.285 \\
\hline
\end{tabular}

$H F$, heart failure; n.a., not available. SUCRA is a transformation of the mean rank that accounts both for the location and the variance of all relative treatment effects. SUCRA would be 1 when a treatment is certain to be the best and 0 when a treatment is certain to be the worst [19] cardiovascular outcome trials, since these trials contribute more than $90 \%$ of mortality events to the present analysis. In the EMPA-REG-OUTCOME trial, empagliflozin significantly reduced all-cause and cardiovascular mortality in 7020
Fig. 3 Predictive interval plot for cardiovascular mortality. Legend: The predictive interval plot represents a forest plot of the joint estimated summary effects from both direct and indirect comparisons along with their confidence intervals. Significant results are shown in red colour

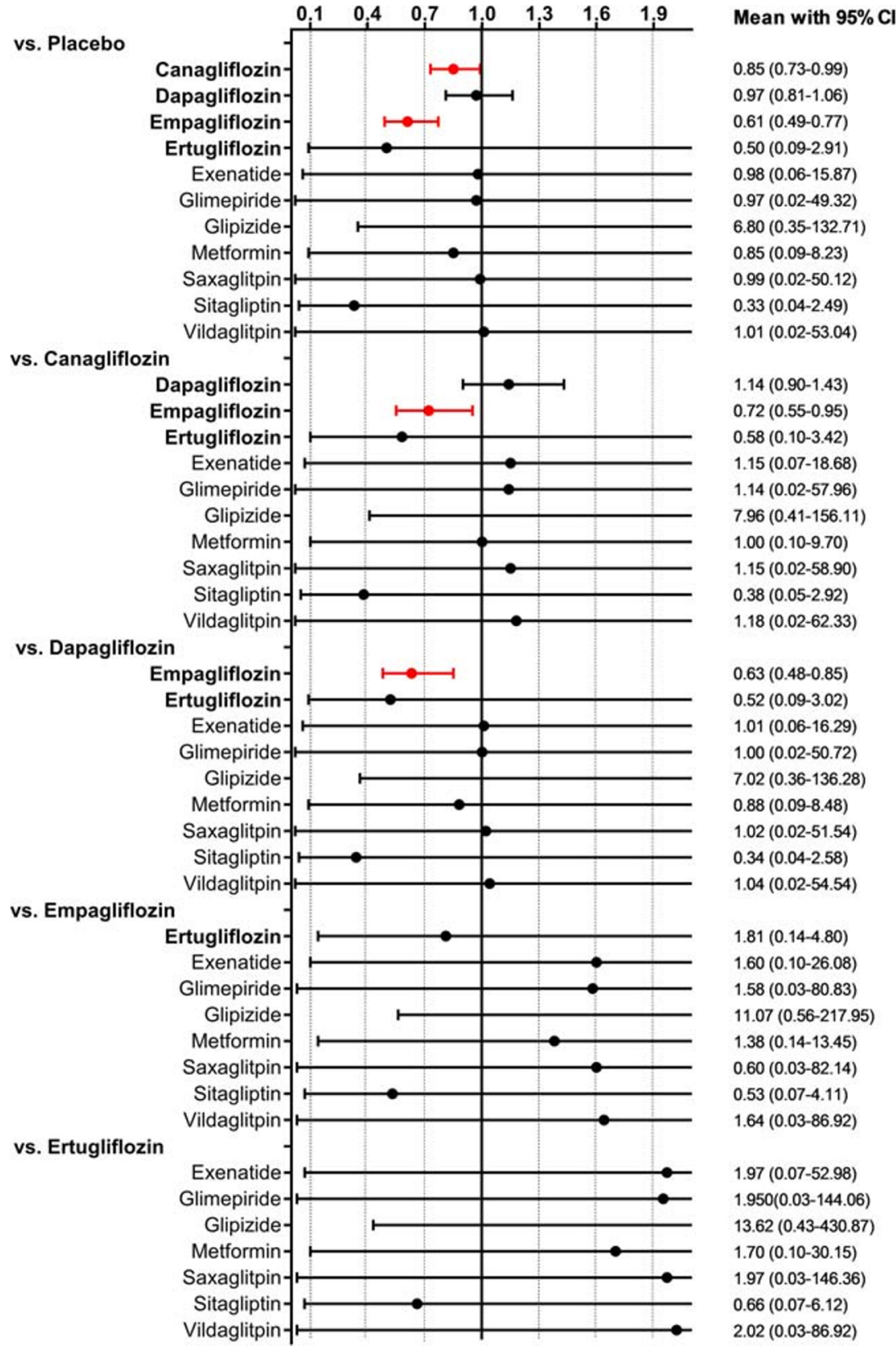


Fig. 4 Predictive interval plot for worsening HF. Legend: The predictive interval plot represents a forest plot of the joint estimated summary effects from both direct and indirect comparisons along with their confidence intervals. Significant results are shown in red colour

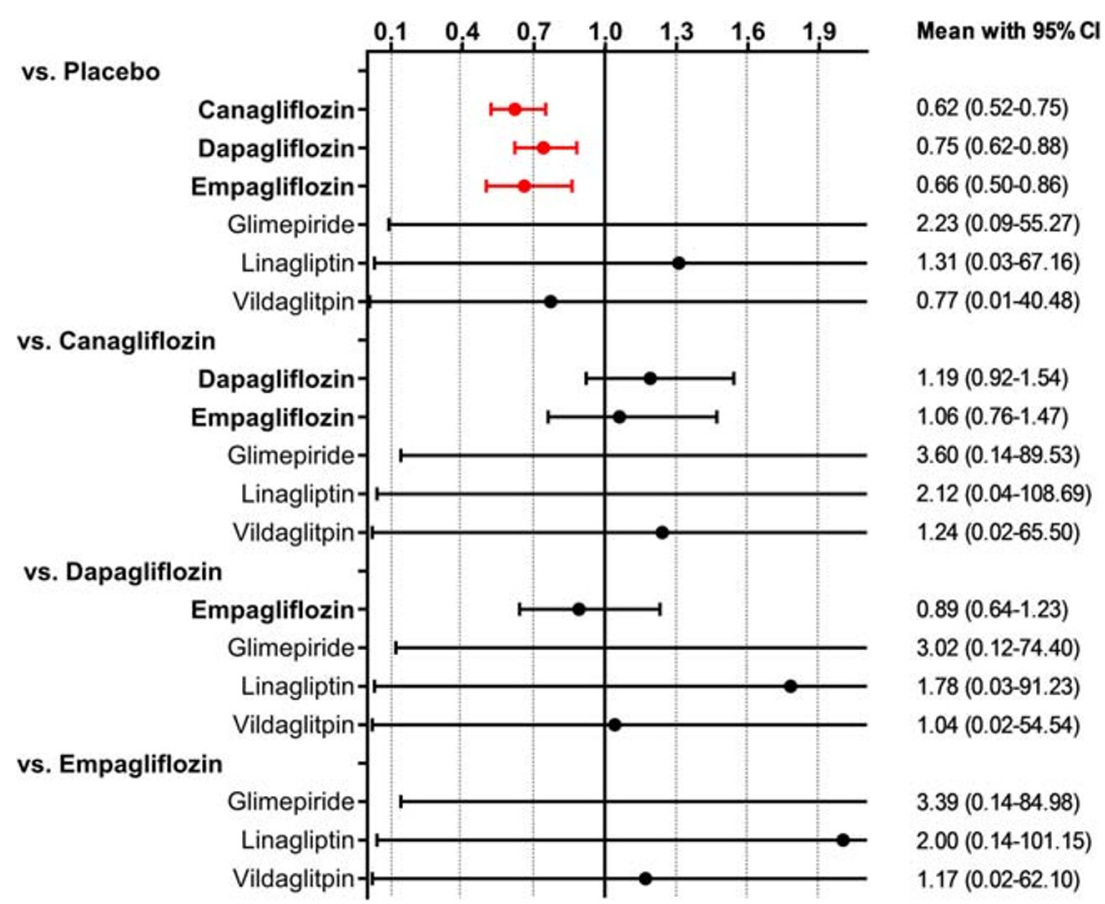

patients with T2D at high cardiovascular risk [6]. In contrast, dapagliflozin had a neutral effect on survival in 17,160 patients included in the DECLARE-TIMI 58 trial [5]. Similarly, canagliflozin did not affect overall survival or cardiovascular death both in 10,142 patients enrolled in the CANVAS programme and in 4401 patients enrolled in the CREDENCE trial $[4,61]$, though in all cases, the $95 \%$ CI of the effect measure just touched the null-effect line.

Our findings may reflect features of trial designs or actual differences between the agents. Although molecules of dapagliflozin and canagliflozin are very similar to those of empagliflozin, small differences in the molecular structure can potentially lead to critical differences. For example, the molecular differences between the hormones testosterone and estradiol are substantially smaller than the differences between the empagliflozin molecule and the other two members of the class [88]. However, individual SGLT2i share their mode of action as well as important pharmacological characteristics including bioavailability, receptor selectivity, metabolism, elimination half-life and excretion [89, 90]. In addition, they have comparable effects on blood glucose, body weight and blood pressure, which are the suggested mediators of the antiatherosclerotic effects of SGLT2i.

The difference in survival benefit between individual SGLT2i may potentially be explained by differences in trial populations. For example, the number of patients with established atherosclerotic cardiovascular disease in EMPAREG-OUTCOME was significantly higher than in the other trials. The mortality rate in the placebo group of the EMPAREG-OUTCOME trial was higher than in the other SGLT2i cardiovascular outcome trials, highlighting the differences between populations. An additional factor is that the number of patients with concomitant chronic kidney disease varied between trials. As patients with impaired renal function may gain a greater benefit from SGLT2i therapy, exclusion of these patients from the DECLARE-TIMI 58 trial may have limited mortality benefits [91].

To date, data on the cardiovascular effects of ertugliflozin are scarce. The present NMA includes seven trials totalling 4740 patients treated with ertugliflozin; however, these trials reported only 17 deaths. Due to the low number of events, mortality analyses result in wide confidence intervals and should therefore be interpreted with caution. The cardiovascular efficacy and safety of ertugliflozin in patients with T2D is currently being evaluated in the VERTIS-CV trial. The trial completed enrolment in 2017 and the results are expected to be published in 2020 [92].

The present NMA shows a clear reduction in HF events with canagliflozin, dapagliflozin and empagliflozin, with no significant difference between individual SGLT2i. Again, these results are mainly driven by the four large-scale cardiovascular outcome trials, which reported a relative 30-40\% risk reduction for worsening HF for each agent [4-6, 61]. Notably, the benefit was independent of baseline cardiovascular risk or a history of HF [93-95]. The benefits with SGLT2i for HF outcomes may be secondary to a reduction in circulating volume and other haemodynamic effects with a reduction of myocardial loading [93-95]. Natriuresis [96], systemic blood pressure lowering [97], modification of the intrarenal renin angiotensin axis [98] and reduction in arterial stiffness [99] 
may all contribute to the protection afforded [94]. These effects have been reported for all the different SGLT2i, consistent with the comparable HF efficacy of individual SGLT2i.

In the present NMA, no significant differences in mortality or HF efficacy were found when comparing individual SGLT2 $\mathrm{i}$ to other active treatments. This contrasts to two recently published meta-analyses in which the use of SGLT2 inhibitors was associated with lower mortality and a lower risk of HF compared with dipeptidyl peptidase 4 inhibitors $[100,101]$. The meta-analyses, however, compared classes of drugs, whereas the present NMA presents comparisons of individual agents. As the number of events included in each analysis is low, comparisons of individual SGLT2i with other active treatments need to be interpreted with caution.

\section{Limitations}

The present NMA includes all the available evidence regarding the effects of SGLT2i on commonly accepted endpoints in patients with T2D. It deliberately excludes the recently published DAPA-HF trial [102]. This is because all trials (except DAPA-HF) included T2D patients - of whom some had chronic HF-while DAPA-HF included only chronic HF patients — of whom some had T2D. This would substantially skew baseline characteristics between DAPA-HF and all other studies. The ensuing violation of the transitivity assumption would thus invalidate the entire NMA. Several other potential study limitations should be considered.

First, most trials in the present NMA included a relatively small number of patients, with four trials contributing almost half of the study population.

Second, the mean follow-up duration of the core trials was 40 weeks, which limits mortality analyses. However, our results were confirmed in a sensitivity analysis restricted to trials with a treatment duration of at least 52 weeks.

Third, the majority of studies included were not designed as cardiovascular outcome trials. They were therefore not powered to detect differences in survival between active treatments and comparators. However, aggregation of individual trial data in a (network) meta-analysis is an appropriate tool to increase the power and validity of individual study results. In addition, we confirmed the results of our NMA in a sensitivity analysis that excluded non-cardiovascular outcome trials.

Fourth, baseline cardiovascular risk - if reported at allvaried substantially between trials, with a significantly higher number of patients with established atherosclerotic cardiovascular disease included in empagliflozin trials. As patients at high cardiovascular risk may gain a greater benefit from SGLT2i therapy, differences between trial populations may have biased the results. In addition, differences in background anti-diabetic and/or cardiovascular treatment may have affected the number of cardiovascular endpoints.
Fifth, statistically significant results from a (network) metaanalysis do not necessarily imply clinically meaningful differences in efficacy. The findings of the present study should therefore be interpreted cautiously.

\section{Conclusion}

We found similar reductions in worsening HF with empagliflozin, canagliflozin and dapagliflozin. However, empagliflozin was associated with a greater reduction in allcause and cardiovascular mortality. Due to the low number of events reported from ertugliflozin trials, no reliable conclusions on cardiovascular outcomes may be drawn from ertugliflozin analyses. Although the differences in the efficacy of individual SGLT2i might reflect different trial designs, clinicians may prefer empagliflozin over other SGLT2i until more evidence on the comparative efficacy of SGLT2i is available.

Acknowledgements Open Access funding provided by Projekt DEAL.

Authors' contribution All authors contributed to the study conception and design. Material preparation, data collection and analysis were performed by Tobias Täger, Hanna Fröhlich and Lutz Frankenstein. The first draft of the manuscript was written by Tobias Täger and all authors commented on previous versions of the manuscript. All authors read and approved the final manuscript.

\section{Compliance with ethical standards}

Conflict of interest Prof. Agewall and Prof. Atar report personal fees from Boehringer Ingelheim (outside the submitted work). Prof. Cleland reports grants and personal fees from Abbott, Amgen, Bayer, Bristol-Myers Squibb, and Torrent Pharmaceuticals; personal fees from AstraZeneca and Myokardia; grants, personal fees and non-financial support from Medtronic, Novartis, and Vifor; grants and non-financial support from Pharmacosmos and PharmaNord (outside the submitted work). Prof. Katus reports personal fees from AstraZeneca, Boehringer Ingelheim, Roche Diagnostics, Bayer Vital, and Daiichi Sankyo (outside the submitted work).

Open Access This article is licensed under a Creative Commons Attribution 4.0 International License, which permits use, sharing, adaptation, distribution and reproduction in any medium or format, as long as you give appropriate credit to the original author(s) and the source, provide a link to the Creative Commons licence, and indicate if changes were made. The images or other third party material in this article are included in the article's Creative Commons licence, unless indicated otherwise in a credit line to the material. If material is not included in the article's Creative Commons licence and your intended use is not permitted by statutory regulation or exceeds the permitted use, you will need to obtain permission directly from the copyright holder. To view a copy of this licence, visit http://creativecommons.org/licenses/by/4.0/.

\section{References}

1. Liu XY, Zhang N, Chen R, Zhao JG, Yu P (2015) Efficacy and safety of sodium-glucose cotransporter 2 inhibitors in type 2 
diabetes: a meta-analysis of randomized controlled trials for 1 to 2years. J Diabetes Complicat 29(8):1295-1303. https://doi.org/10. 1016/j.jdiacomp.2015.07.011

2. Donnan JR, Grandy CA, Chibrikov E, Marra CA, Aubrey-Bassler K, Johnston K, Swab M, Hache J, Curnew D, Nguyen H, Gamble JM (2019) Comparative safety of the sodium glucose co-transporter 2 (SGLT2) inhibitors: a systematic review and meta-analysis. BMJ Open 9(1):e022577. https://doi.org/10.1136/bmjopen-2018-022577

3. Zelniker TA, Wiviott SD, Raz I, Im K, Goodrich EL, Bonaca MP, Mosenzon O, Kato ET, Cahn A, Furtado RHM, Bhatt DL, Leiter LA, McGuire DK, Wilding JPH, Sabatine MS (2019) SGLT2 inhibitors for primary and secondary prevention of cardiovascular and renal outcomes in type 2 diabetes: a systematic review and meta-analysis of cardiovascular outcome trials. Lancet 393(10166):31-39. https:// doi.org/10.1016/S0140-6736(18)32590-X

4. Neal B, Perkovic V, Mahaffey KW, de Zeeuw D, Fulcher G, Erondu N, Shaw W, Law G, Desai M, Matthews DR (2017) Canagliflozin and cardiovascular and renal events in type 2 diabetes. N Engl J Med 377(7):644-657. https://doi.org/10.1056/ NEJMoa1611925

5. Wiviott SD, Raz I, Bonaca MP, Mosenzon O, Kato ET, Cahn A, Silverman MG, Zelniker TA, Kuder JF, Murphy SA, Bhatt DL, Leiter LA, McGuire DK, Wilding JPH, Ruff CT, Gause-Nilsson IAM, Fredriksson M, Johansson PA, Langkilde AM, Sabatine MS, Investigators D-T (2019) Dapagliflozin and cardiovascular outcomes in type 2 diabetes. N Engl J Med 380(4):347-357. https://doi.org/10.1056/NEJMoa1812389

6. Zinman B, Wanner C, Lachin JM, Fitchett D, Bluhmki E, Hantel S, Mattheus M, Devins T, Johansen OE, Woerle HJ, Broedl UC, Inzucchi SE (2015) Empagliflozin, cardiovascular outcomes, and mortality in type 2 diabetes. N Engl J Med 373(22):2117-2128. https://doi.org/10.1056/NEJMoa1504720

7. Nissen SE, Wolski K (2007) Effect of rosiglitazone on the risk of myocardial infarction and death from cardiovascular causes. N Engl J Med 356(24):2457-2471. https://doi.org/10.1056/NEJMoa072761

8. Hutton B, Catala-Lopez F, Moher D (2016) The PRISMA statement extension for systematic reviews incorporating network meta-analysis: PRISMA-NMA. Med Clin (Barc) 147(6):262-266. https://doi.org/10.1016/j.medcli.2016.02.025

9. Moher D, Stewart L, Shekelle P (2016) Implementing PRISMAP: recommendations for prospective authors. Syst Rev 5:15. https://doi.org/10.1186/s13643-016-0191-y

10. Shamseer L, Moher D, Clarke M, Ghersi D, Liberati A, Petticrew M, Shekelle P, Stewart LA, Group P-P (2015) Preferred reporting items for systematic review and meta-analysis protocols (PRISMA-P) 2015: elaboration and explanation. BMJ 349: g7647. https://doi.org/10.1136/bmj.g7647

11. Moher D, Shamseer L, Clarke M, Ghersi D, Liberati A, Petticrew M, Shekelle P, Stewart LA, Group P-P (2015) Preferred reporting items for systematic review and meta-analysis protocols (PRISMA-P) 2015 statement. Syst Rev 4:1. https://doi.org/10. 1186/2046-4053-4-1

12. Higgins J, Green S (eds) Cochrane handbook for systematic reviews of interventions version 5.1.0 [updated March 2011]

13. Higgins JP, Jackson D, Barrett JK, Lu G, Ades AE, White IR (2012) Consistency and inconsistency in network meta-analysis: concepts and models for multi-arm studies. Res Synth Methods 3(2):98-110. https://doi.org/10.1002/jrsm.1044

14. Chaimani A, Higgins JP, Mavridis D, Spyridonos P, Salanti G (2013) Graphical tools for network meta-analysis in STATA. PLoS One 8(10):e76654. https://doi.org/10.1371/journal.pone. 0076654

15. Salanti G (2012) Indirect and mixed-treatment comparison, network, or multiple-treatments meta-analysis: many names, many benefits, many concerns for the next generation evidence synthesis tool. Res Synth Methods 3(2):80-97. https://doi.org/10.1002/ jrsm. 1037

16. Salanti G, Marinho V, Higgins JP (2009) A case study of multipletreatments meta-analysis demonstrates that covariates should be considered. J Clin Epidemiol 62(8):857-864. https://doi.org/10. 1016/j.jclinepi.2008.10.001

17. Salanti G, Del Giovane C, Chaimani A, Caldwell DM, Higgins JP (2014) Evaluating the quality of evidence from a network metaanalysis. PLoS One 9(7):e99682. https://doi.org/10.1371/journal. pone.0099682

18. Puhan MA, Schunemann HJ, Murad MH, Li T, BrignardelloPetersen R, Singh JA, Kessels AG, Guyatt GH, Group GW (2014) A GRADE Working Group approach for rating the quality of treatment effect estimates from network meta-analysis. BMJ 349:g5630. https://doi.org/10.1136/bmj.g5630

19. Salanti G, Ades AE, Ioannidis JP (2011) Graphical methods and numerical summaries for presenting results from multipletreatment meta-analysis: an overview and tutorial. J Clin Epidemiol 64(2):163-171. https://doi.org/10.1016/j.jclinepi. 2010.03.016

20. Mbuagbaw L, Rochwerg B, Jaeschke R, Heels-Andsell D, Alhazzani W, Thabane L, Guyatt GH (2017) Approaches to interpreting and choosing the best treatments in network metaanalyses. Syst Rev 6(1):79. https://doi.org/10.1186/s13643-0170473-z

21. Song F, Harvey I, Lilford R (2008) Adjusted indirect comparison may be less biased than direct comparison for evaluating new pharmaceutical interventions. J Clin Epidemiol 61(5):455-463. https://doi.org/10.1016/j.jclinepi.2007.06.006

22. Bailey CJ, Gross JL, Pieters A, Bastien A, List JF (2010) Effect of dapagliflozin in patients with type 2 diabetes who have inadequate glycaemic control with metformin: a randomised, double-blind, placebo-controlled trial. Lancet 375(9733):2223-2233. https:// doi.org/10.1016/S0140-6736(10)60407-2

23. Bailey CJ, Iqbal N, T'Joen C, List JF (2012) Dapagliflozin monotherapy in drug-naive patients with diabetes: a randomizedcontrolled trial of low-dose range. Diabetes Obes Metab 14(10): 951-959. https://doi.org/10.1111/j.1463-1326.2012.01659.x

24. Barnett AH, Mithal A, Manassie J, Jones R, Rattunde H, Woerle HJ, Broedl UC, investigators E-RRt (2014) Efficacy and safety of empagliflozin added to existing antidiabetes treatment in patients with type 2 diabetes and chronic kidney disease: a randomised, double-blind, placebo-controlled trial. Lancet Diabetes Endocrinol 2(5):369-384. https://doi.org/10.1016/S22138587(13)70208-0

25. Bode B, Stenlof K, Sullivan D, Fung A, Usiskin K (2013) Efficacy and safety of canagliflozin treatment in older subjects with type 2 diabetes mellitus: a randomized trial. Hosp Pract (1995) 41(2):7284. https://doi.org/10.3810/hp.2013.04.1020

26. Bolinder $\mathrm{J}$, Ljunggren $\mathrm{O}$, Kullberg J, Johansson L, Wilding J, Langkilde AM, Sugg J, Parikh S (2012) Effects of dapagliflozin on body weight, total fat mass, and regional adipose tissue distribution in patients with type 2 diabetes mellitus with inadequate glycemic control on metformin. J Clin Endocrinol Metab 97(3): 1020-1031. https://doi.org/10.1210/jc.2011-2260

27. Bolinder J, Ljunggren O, Johansson L, Wilding J, Langkilde AM, Sjostrom CD, Sugg J, Parikh S (2014) Dapagliflozin maintains glycaemic control while reducing weight and body fat mass over 2 years in patients with type 2 diabetes mellitus inadequately controlled on metformin. Diabetes Obes Metab 16(2):159-169. https://doi.org/10.1111/dom.12189

28. Cefalu WT, Leiter LA, Yoon KH, Arias P, Niskanen L, Xie J, Balis DA, Canovatchel W, Meininger G (2013) Efficacy and safety of canagliflozin versus glimepiride in patients with type 2 diabetes inadequately controlled with metformin (CANTATA-SU): 52 week results from a randomised, double-blind, phase 3 non- 
inferiority trial. Lancet 382(9896):941-950. https://doi.org/10. 1016/S0140-6736(13)60683-2

29. Cefalu WT, Leiter LA, de Bruin TW, Gause-Nilsson I, Sugg J, Parikh SJ (2015) Dapagliflozin's effects on glycemia and cardiovascular risk factors in high-risk patients with type 2 diabetes: a 24-week, multicenter, randomized, double-blind, placebocontrolled study with a 28-week extension. Diabetes Care 38(7): 1218-1227. https://doi.org/10.2337/dc14-0315

30. Dagogo-Jack S, Liu J, Eldor R, Amorin G, Johnson J, Hille D, Liao Y, Huyck S, Golm G, Terra SG, Mancuso JP, Engel SS, Lauring B (2018) Efficacy and safety of the addition of ertugliflozin in patients with type 2 diabetes mellitus inadequately controlled with metformin and sitagliptin: the VERTIS SITA2 placebo-controlled randomized study. Diabetes Obes Metab 20(3):530-540. https://doi.org/10.1111/dom.13116

31. DeFronzo RA, Lewin A, Patel S, Liu D, Kaste R, Woerle HJ, Broedl UC (2015) Combination of empagliflozin and linagliptin as second-line therapy in subjects with type 2 diabetes inadequately controlled on metformin. Diabetes Care 38(3):384-393. https:// doi.org/10.2337/dc14-2364

32. Ferdinand KC, Izzo JL, Lee J, Meng L, George J, Salsali A, Seman L (2019) Antihyperglycemic and blood pressure effects of empagliflozin in African Americans with type 2 diabetes and hypertension. Circulation. https://doi.org/10.1161/ CIRCULATIONAHA.118.036568

33. Ferrannini E, Ramos SJ, Salsali A, Tang W, List JF (2010) Dapagliflozin monotherapy in type 2 diabetic patients with inadequate glycemic control by diet and exercise: a randomized, double-blind, placebo-controlled, phase 3 trial. Diabetes Care 33(10): 2217-2224. https://doi.org/10.2337/dc10-0612

34. Fioretto P, Del Prato S, Buse JB, Goldenberg R, Giorgino F, Reyner D, Langkilde AM, Sjostrom CD, Sartipy P, Investigators DS (2018) Efficacy and safety of dapagliflozin in patients with type 2 diabetes and moderate renal impairment (chronic kidney disease stage 3A): the DERIVE Study. Diabetes Obes Metab 20(11):2532-2540. https://doi.org/10.1111/dom.13413

35. Forst T, Guthrie R, Goldenberg R, Yee J, Vijapurkar U, Meininger G, Stein P (2014) Efficacy and safety of canagliflozin over 52 weeks in patients with type 2 diabetes on background metformin and pioglitazone. Diabetes Obes Metab 16(5):467-477. https:// doi.org/10.1111/dom.12273

36. Frias JP, Guja C, Hardy E, Ahmed A, Dong F, Ohman P, Jabbour SA (2016) Exenatide once weekly plus dapagliflozin once daily versus exenatide or dapagliflozin alone in patients with type 2 diabetes inadequately controlled with metformin monotherapy (DURATION-8): a 28 week, multicentre, double-blind, phase 3, randomised controlled trial. Lancet Diabetes Endocrinol 4(12): 1004-1016. https://doi.org/10.1016/S2213-8587(16)30267-4

37. Jabbour SA, Frias JP, Hardy E, Ahmed A, Wang H, Ohman P, Guja C (2018) Safety and efficacy of exenatide once weekly plus dapagliflozin once daily versus exenatide or dapagliflozin alone in patients with type 2 diabetes inadequately controlled with metformin monotherapy: 52-week results of the DURATION-8 randomized controlled trial. Diabetes Care 41(10):2136-2146. https://doi. org/10.2337/dc18-0680

38. Grunberger G, Camp S, Johnson J, Huyck S, Terra SG, Mancuso JP, Jiang ZW, Golm G, Engel SS, Lauring B (2018) Ertugliflozin in patients with stage 3 chronic kidney disease and type 2 diabetes mellitus: the VERTIS RENAL randomized study. Diabetes Ther 9(1):49-66. https://doi.org/10.1007/s13300-017-0337-5

39. Hadjadj S, Rosenstock J, Meinicke T, Woerle HJ, Broedl UC (2016) Initial combination of empagliflozin and metformin in patients with type 2 diabetes. Diabetes Care 39(10):1718-1728. https://doi.org/10.2337/dc16-0522

40. Haring HU, Merker L, Seewaldt-Becker E, Weimer M, Meinicke T, Woerle HJ, Broedl UC, Investigators E-RMT (2013)
Empagliflozin as add-on to metformin plus sulfonylurea in patients with type 2 diabetes: a 24-week, randomized, double-blind, placebo-controlled trial. Diabetes Care 36(11):3396-3404. https:// doi.org/10.2337/dc12-2673

41. Haring HU, Merker L, Seewaldt-Becker E, Weimer M, Meinicke T, Broedl UC, Woerle HJ, Investigators E-RMT (2014) Empagliflozin as add-on to metformin in patients with type 2 diabetes: a 24-week, randomized, double-blind, placebocontrolled trial. Diabetes Care 37(6):1650-1659. https://doi.org/ $10.2337 / \mathrm{dc} 13-2105$

42. Henry RR, Murray AV, Marmolejo MH, Hennicken D, Ptaszynska A, List JF (2012) Dapagliflozin, metformin XR, or both: initial pharmacotherapy for type 2 diabetes, a randomised controlled trial. Int J Clin Pract 66(5):446-456. https://doi.org/10.1111/j. 1742-1241.2012.02911.x

43. Hollander P, Liu J, Hill J, Johnson J, Jiang ZW, Golm G, Huyck S, Terra SG, Mancuso JP, Engel SS, Lauring B (2018) Ertugliflozin compared with glimepiride in patients with type 2 diabetes mellitus inadequately controlled on metformin: the VERTIS SU randomized study. Diabetes Ther 9(1):193-207. https://doi.org/ 10.1007/s13300-017-0354-4

44. Hollander P, Liu J, Hill J, Johnson J, Jiang ZW, Wang D, Golm G, Huyck S, Terra S, Mancuso JP et al (2018) Safety and efficacy of ertugliflozin compared with glimepiride after 104 weeks in patients with type 2 diabetes inadequately controlled on metformin: VERTIS SU extension. Diabetologia Conference: 54th annual meeting of the European association for the study diabetes, EASD 2018 Germany 61 (Supplement 1):S304-S305. https:// doi.org/10.1007/s00125-018-4693-0

45. Inagaki N, Kondo K, Yoshinari T, Takahashi N, Susuta Y, Kuki H (2014) Efficacy and safety of canagliflozin monotherapy in Japanese patients with type 2 diabetes inadequately controlled with diet and exercise: a 24-week, randomized, double-blind, placebo-controlled, phase III study. Expert Opin Pharmacother 15(11):1501-1515. https://doi.org/10.1517/14656566.2014. 935764

46. Jabbour SA, Hardy E, Sugg J, Parikh S, Study G (2014) Dapagliflozin is effective as add-on therapy to sitagliptin with or without metformin: a 24-week, multicenter, randomized, doubleblind, placebo-controlled study. Diabetes Care 37(3):740-750. https://doi.org/10.2337/dc13-0467

47. Ji L, Ma J, Li H, Mansfield TA, T'Joen CL, Iqbal N, Ptaszynska A, List JF (2014) Dapagliflozin as monotherapy in drug-naive Asian patients with type 2 diabetes mellitus: a randomized, blinded, prospective phase III study. Clin Ther 36(1):84-100.e109. https://doi. org/10.1016/j.clinthera.2013.11.002

48. Kadowaki T, Inagaki N, Kondo K, Nishimura K, Kaneko G, Maruyama N, Nakanishi N, Iijima H, Watanabe Y, Gouda M (2017) Efficacy and safety of canagliflozin as add-on therapy to teneligliptin in Japanese patients with type 2 diabetes mellitus: results of a 24-week, randomized, double-blind, placebocontrolled trial. Diabetes Obes Metab 19(6):874-882. https://doi. org/10.1111/dom.12898

49. Kaku K, Kiyosue A, Inoue S, Ueda N, Tokudome T, Yang J, Langkilde AM (2014) Efficacy and safety of dapagliflozin monotherapy in Japanese patients with type 2 diabetes inadequately controlled by diet and exercise. Diabetes Obes Metab 16(11): 1102-1110. https://doi.org/10.1111/dom.12325

50. Kohan DE, Fioretto P, Tang W, List JF (2014) Long-term study of patients with type 2 diabetes and moderate renal impairment shows that dapagliflozin reduces weight and blood pressure but does not improve glycemic control. Kidney Int 85(4):962-971. https://doi.org/10.1038/ki.2013.356

51. Kovacs CS, Seshiah V, Swallow R, Jones R, Rattunde H, Woerle HJ, Broedl UC, investigators E-RPt (2014) Empagliflozin improves glycaemic and weight control as add-on therapy to 
pioglitazone or pioglitazone plus metformin in patients with type 2 diabetes: a 24-week, randomized, placebo-controlled trial. Diabetes Obes Metab 16(2):147-158. https://doi.org/10.1111/ dom. 12188

52. Kovacs CS, Seshiah V, Merker L, Christiansen AV, Roux F, Salsali A, Kim G, Stella P, Woerle HJ, Broedl UC, investigators E-REP (2015) Empagliflozin as add-on therapy to pioglitazone with or without metformin in patients with type 2 diabetes mellitus. Clin Ther 37(8):1773-1788 e1771. https://doi.org/10.1016/j.clinthera. 2015.05.511

53. Lavalle-Gonzalez FJ, Januszewicz A, Davidson J, Tong C, Qiu R, Canovatchel W, Meininger G (2013) Efficacy and safety of canagliflozin compared with placebo and sitagliptin in patients with type 2 diabetes on background metformin monotherapy: a randomised trial. Diabetologia 56(12):2582-2592. https://doi.org/ 10.1007/s00125-013-3039-1

54. Leiter LA, Cefalu WT, de Bruin TW, Gause-Nilsson I, Sugg J, Parikh SJ (2014) Dapagliflozin added to usual care in individuals with type 2 diabetes mellitus with preexisting cardiovascular disease: a 24-week, multicenter, randomized, double-blind, placebocontrolled study with a 28 -week extension. J Am Geriatr Soc 62(7):1252-1262. https://doi.org/10.1111/jgs. 12881

55. Lewin A, DeFronzo RA, Patel S, Liu D, Kaste R, Woerle HJ, Broedl UC (2015) Initial combination of empagliflozin and linagliptin in subjects with type 2 diabetes. Diabetes Care 38(3): 394-402. https://doi.org/10.2337/dc14-2365

56. Mathieu C, Ranetti AE, Li D, Ekholm E, Cook W, Hirshberg B, Chen H, Hansen L, Iqbal N (2015) Randomized, double-blind, phase 3 trial of triple therapy with dapagliflozin add-on to saxagliptin plus metformin in type 2 diabetes. Diabetes Care 38(11):2009-2017. https://doi.org/10.2337/dc15-0779

57. Mathieu C, Herrera Marmolejo M, Gonzalez Gonzalez JG, Hansen L, Chen H, Johnsson E, Garcia-Sanchez R, Iqbal N (2016) Efficacy and safety of triple therapy with dapagliflozin add-on to saxagliptin plus metformin over 52 weeks in patients with type 2 diabetes. Diabetes Obes Metab 18(11):1134-1137. https://doi.org/10.1111/dom.12737

58. Matthaei S, Bowering K, Rohwedder K, Grohl A, Parikh S, Study G (2015) Dapagliflozin improves glycemic control and reduces body weight as add-on therapy to metformin plus sulfonylurea: a 24-week randomized, double-blind clinical trial. Diabetes Care 38(3):365-372. https://doi.org/10.2337/dc14-0666

59. Muller-Wieland D, Kellerer M, Cypryk K, Skripova D, Rohwedder K, Johnsson E, Garcia-Sanchez R, Kurlyandskaya R, Sjostrom CD, Jacob S, Seufert J, Dronamraju N, Csomos K (2018) Efficacy and safety of dapagliflozin or dapagliflozin plus saxagliptin versus glimepiride as add-on to metformin in patients with type 2 diabetes. Diabetes Obes Metab 20(11):2598-2607. https://doi.org/10.1111/dom.13437

60. Nauck MA, Del Prato S, Meier JJ, Duran-Garcia S, Rohwedder K, Elze M, Parikh SJ (2011) Dapagliflozin versus glipizide as add-on therapy in patients with type 2 diabetes who have inadequate glycemic control with metformin: a randomized, 52-week, doubleblind, active-controlled noninferiority trial. Diabetes Care 34(9): 2015-2022. https://doi.org/10.2337/dc11-0606

61. Perkovic V, Jardine MJ, Neal B, Bompoint S, Heerspink HJL, Charytan DM, Edwards R, Agarwal R, Bakris G, Bull S, Cannon CP, Capuano G, Chu PL, de Zeeuw D, Greene T, Levin A, Pollock C, Wheeler DC, Yavin Y, Zhang H, Zinman B, Meininger G, Brenner BM, Mahaffey KW (2019) Canagliflozin and renal outcomes in type 2 diabetes and nephropathy. N Engl J Med 380(24):2295-2306. https://doi.org/10.1056/ NEJMoa1811744

62. Phrommintikul A, Wongcharoen W, Kumfu S, Jaiwongkam T, Gunaparn S, Chattipakorn S, Chattipakorn N (2019) Effects of dapagliflozin vs vildagliptin on cardiometabolic parameters in diabetic patients with coronary artery disease: a randomised study. Br J Clin Pharmacol 85(6):1337-1347. https://doi.org/10.1111/ bcp.13903

63. Pollock C, Stefansson B, Reyner D, Rossing P, Sjostrom CD, Wheeler DC, Langkilde AM, Heerspink HJL (2019) Albuminuria-lowering effect of dapagliflozin alone and in combination with saxagliptin and effect of dapagliflozin and saxagliptin on glycaemic control in patients with type 2 diabetes and chronic kidney disease (DELIGHT): a randomised, double-blind, placebocontrolled trial. Lancet Diabetes Endocrinol 7(6):429-441. https:// doi.org/10.1016/S2213-8587(19)30086-5

64. Pratley RE, Eldor R, Raji A, Golm G, Huyck SB, Qiu Y, Sunga S, Johnson J, Terra SG, Mancuso JP, Engel SS, Lauring B (2018) Ertugliflozin plus sitagliptin versus either individual agent over 52 weeks in patients with type 2 diabetes mellitus inadequately controlled with metformin: the VERTIS FACTORIAL randomized trial. Diabetes Obes Metab 20(5):1111-1120. https://doi.org/10. 1111/dom.13194

65. Ridderstrale M, Andersen KR, Zeller C, Kim G, Woerle HJ, Broedl UC, investigators E-RHHSt (2014) Comparison of empagliflozin and glimepiride as add-on to metformin in patients with type 2 diabetes: a 104-week randomised, active-controlled, double-blind, phase 3 trial. Lancet Diabetes Endocrinol 2(9):691700. https://doi.org/10.1016/S2213-8587(14)70120-2

66. Ridderstrale M, Rosenstock J, Andersen KR, Woerle HJ, Salsali A, investigators E-RHHSt (2018) Empagliflozin compared with glimepiride in metformin-treated patients with type 2 diabetes: 208-week data from a masked randomized controlled trial. Diabetes Obes Metab 20(12):2768-2777. https://doi.org/10. 1111/dom. 13457

67. Rodbard HW, Seufert J, Aggarwal N, Cao A, Fung A, Pfeifer M, Alba M (2016) Efficacy and safety of titrated canagliflozin in patients with type 2 diabetes mellitus inadequately controlled on metformin and sitagliptin. Diabetes Obes Metab 18(8):812-819. https://doi.org/10.1111/dom.12684

68. Roden M, Weng J, Eilbracht J, Delafont B, Kim G, Woerle HJ, Broedl UC, investigators E-RMt (2013) Empagliflozin monotherapy with sitagliptin as an active comparator in patients with type 2 diabetes: a randomised, double-blind, placebo-controlled, phase 3 trial. Lancet Diabetes Endocrinol 1(3):208-219. https://doi.org/ 10.1016/S2213-8587(13)70084-6

69. Roden M, Merker L, Christiansen AV, Roux F, Salsali A, Kim G, Stella P, Woerle HJ, Broedl UC, investigators E-REM (2015) Safety, tolerability and effects on cardiometabolic risk factors of empagliflozin monotherapy in drug-naive patients with type 2 diabetes: a double-blind extension of a phase III randomized controlled trial. Cardiovasc Diabetol 14:154. https://doi.org/10.1186/ s12933-015-0314-0

70. Rosenstock J, Vico M, Wei L, Salsali A, List JF (2012) Effects of dapagliflozin, an SGLT2 inhibitor, on $\mathrm{HbA}(1 \mathrm{c})$, body weight, and hypoglycemia risk in patients with type 2 diabetes inadequately controlled on pioglitazone monotherapy. Diabetes Care 35(7): 1473-1478. https://doi.org/10.2337/dc11-1693

71. Rosenstock J, Hansen L, Zee P, Li Y, Cook W, Hirshberg B, Iqbal N (2015) Dual add-on therapy in type 2 diabetes poorly controlled with metformin monotherapy: a randomized double-blind trial of saxagliptin plus dapagliflozin addition versus single addition of saxagliptin or dapagliflozin to metformin. Diabetes Care 38(3): 376-383. https://doi.org/10.2337/dc14-1142

72. Rosenstock J, Jelaska A, Zeller C, Kim G, Broedl UC, Woerle HJ, investigators E-RBt (2015) Impact of empagliflozin added on to basal insulin in type 2 diabetes inadequately controlled on basal insulin: a 78-week randomized, double-blind, placebo-controlled trial. Diabetes Obes Metab 17(10):936-948. https://doi.org/10. 1111/dom. 12503 
73. Rosenstock J, Chuck L, Gonzalez-Ortiz M, Merton K, Craig J, Capuano G, Qiu R (2016) Initial combination therapy with canagliflozin plus metformin versus each component as monotherapy for drug-naive type 2 diabetes. Diabetes Care 39(3):353-362. https://doi.org/10.2337/dc15-1736

74. Rosenstock J, Frias J, Pall D, Charbonnel B, Pascu R, Saur D, Darekar A, Huyck S, Shi H, Lauring B, Terra SG (2018) Effect of ertugliflozin on glucose control, body weight, blood pressure and bone density in type 2 diabetes mellitus inadequately controlled on metformin monotherapy (VERTIS MET). Diabetes Obes Metab 20(3):520-529. https://doi.org/10.1111/dom.13103

75. Schernthaner G, Gross JL, Rosenstock J, Guarisco M, Fu M, Yee J, Kawaguchi M, Canovatchel W, Meininger G (2013) Canagliflozin compared with sitagliptin for patients with type 2 diabetes who do not have adequate glycemic control with metformin plus sulfonylurea: a 52-week randomized trial. Diabetes Care 36(9):2508-2515. https://doi.org/10.2337/dc12-2491

76. Scott R, Morgan J, Zimmer Z, Lam RLH, O'Neill EA, Kaufman KD, Engel SS, Raji A (2018) A randomized clinical trial of the efficacy and safety of sitagliptin compared with dapagliflozin in patients with type 2 diabetes mellitus and mild renal insufficiency: the CompoSIT-R study. Diabetes Obes Metab 20(12):2876-2884. https://doi.org/10.1111/dom.13473

77. Softeland E, Meier JJ, Vangen B, Toorawa R, MaldonadoLutomirsky M, Broedl UC (2017) Empagliflozin as add-on therapy in patients with type 2 diabetes inadequately controlled with linagliptin and metformin: a 24-week randomized, double-blind, parallel-group trial. Diabetes Care 40(2):201-209. https://doi.org/ $10.2337 / \mathrm{dc} 16-1347$

78. Stenlof K, Cefalu WT, Kim KA, Alba M, Usiskin K, Tong C, Canovatchel W, Meininger G (2013) Efficacy and safety of canagliflozin monotherapy in subjects with type 2 diabetes mellitus inadequately controlled with diet and exercise. Diabetes Obes Metab 15(4):372-382. https://doi.org/10.1111/dom.12054

79. Strojek K, Yoon KH, Hruba V, Elze M, Langkilde AM, Parikh S (2011) Effect of dapagliflozin in patients with type 2 diabetes who have inadequate glycaemic control with glimepiride: a randomized, 24-week, double-blind, placebo-controlled trial. Diabetes Obes Metab 13(10):928-938. https://doi.org/10.1111/j.14631326.2011.01434.x

80. Strojek K, Yoon KH, Hruba V, Sugg J, Langkilde AM, Parikh S (2014) Dapagliflozin added to glimepiride in patients with type 2 diabetes mellitus sustains glycemic control and weight loss over 48 weeks: a randomized, double-blind, parallel-group, placebocontrolled trial. Diabetes Ther 5(1):267-283. https://doi.org/10. 1007/s13300-014-0072-0

81. Terra SG, Focht K, Davies M, Frias J, Derosa G, Darekar A, Golm G, Johnson J, Saur D, Lauring B, Dagogo-Jack S (2017) Phase III, efficacy and safety study of ertugliflozin monotherapy in people with type 2 diabetes mellitus inadequately controlled with diet and exercise alone. Diabetes Obes Metab 19(5):721-728. https://doi. org/10.1111/dom. 12888

82. Wilding JP, Woo V, Soler NG, Pahor A, Sugg J, Rohwedder K, Parikh S, Dapagliflozin 006 Study G (2012) Long-term efficacy of dapagliflozin in patients with type 2 diabetes mellitus receiving high doses of insulin: a randomized trial. Ann Intern Med 156(6): 405-415. https://doi.org/10.7326/0003-4819-156-6-20120320000003

83. Wilding JP, Woo V, Rohwedder K, Sugg J, Parikh S, Dapagliflozin 006 Study G (2014) Dapagliflozin in patients with type 2 diabetes receiving high doses of insulin: efficacy and safety over 2 years. Diabetes Obes Metab 16(2):124-136. https://doi. org $/ 10.1111 /$ dom. 12187

84. Wilding JP, Charpentier G, Hollander P, Gonzalez-Galvez G, Mathieu C, Vercruysse F, Usiskin K, Law G, Black S, Canovatchel W, Meininger G (2013) Efficacy and safety of canagliflozin in patients with type 2 diabetes mellitus inadequately controlled with metformin and sulphonylurea: a randomised trial. Int J Clin Pract 67(12):1267-1282. https://doi.org/10.1111/ijcp. 12322

85. Yale JF, Bakris G, Cariou B, Yue D, David-Neto E, Xi L, Figueroa K, Wajs E, Usiskin K, Meininger G (2013) Efficacy and safety of canagliflozin in subjects with type 2 diabetes and chronic kidney disease. Diabetes Obes Metab 15(5):463-473. https://doi.org/10. 1111/dom. 12090

86. Yang W, Han P, Min KW, Wang B, Mansfield T, T'Joen C, Iqbal N, Johnsson E, Ptaszynska A (2016) Efficacy and safety of dapagliflozin in Asian patients with type 2 diabetes after metformin failure: a randomized controlled trial. J Diabetes 8(6):796808. https://doi.org/10.1111/1753-0407.12357

87. Yang W, Ma J, Li Y, Zhou Z, Kim JH, Zhao J, Ptaszynska A (2018) Dapagliflozin as add-on therapy in Asian patients with type 2 diabetes inadequately controlled on insulin with or without oral antihyperglycemic drugs: a randomized controlled trial. J Diabetes(no pagination). https://doi.org/10.1111/1753-0407. 12634

88. Schernthaner G, Khunti K, Lotan C, Burnier M, Drexel H, Prazny M (2017) Relevance of positive cardiovascular outcome trial results in clinical practice: perspectives from the Academy for Cardiovascular Risk, Outcomes and Safety Studies in Type 2 Diabetes (ACROSS T2D). Ther Clin Risk Manag 13:15691576. https://doi.org/10.2147/tcrm.s144362

89. Scheen AJ (2015) Pharmacodynamics, efficacy and safety of sodium-glucose co-transporter type 2 (SGLT2) inhibitors for the treatment of type 2 diabetes mellitus. Drugs 75(1):33-59. https:// doi.org/10.1007/s40265-014-0337-y

90. Scheen AJ (2014) Evaluating SGLT2 inhibitors for type 2 diabetes: pharmacokinetic and toxicological considerations. Expert Opin Drug Metab Toxicol 10(5):647-663. https://doi.org/10. $1517 / 17425255.2014 .873788$

91. Bloomgarden Z (2018) The kidney and cardiovascular outcome trials. J Diabetes 10(2):88-89. https://doi.org/10.1111/1753-0407. 12616

92. Cannon CP, McGuire DK, Pratley R, Dagogo-Jack S, Mancuso J, Huyck S, Charbonnel B, Shih WJ, Gallo S, Masiukiewicz U, Golm G, Cosentino F, Lauring B, Terra SG (2018) Design and baseline characteristics of the eValuation of ERTugliflozin effIcacy and Safety CardioVascular outcomes trial (VERTISCV). Am Heart J 206:11-23. https://doi.org/10.1016/j.ahj.2018. 08.016

93. Fitchett D, Butler J, van de Borne P, Zinman B, Lachin JM, Wanner C, Woerle HJ, Hantel S, George JT, Johansen OE, Inzucchi SE (2018) Effects of empagliflozin on risk for cardiovascular death and heart failure hospitalization across the spectrum of heart failure risk in the EMPA-REG OUTCOME(R) trial. Eur Heart J 39(5):363-370. https://doi.org/10.1093/eurheartj/ehx511

94. Radholm K, Figtree G, Perkovic V, Solomon SD, Mahaffey KW, de Zeeuw D, Fulcher G, Barrett TD, Shaw W, Desai M, Matthews DR, Neal B (2018) Canagliflozin and heart failure in type 2 diabetes mellitus. Circulation 138(5):458-468. https://doi.org/10. 1161/circulationaha.118.034222

95. Kato ET, Silverman MG, Mosenzon O, Zelniker TA, Cahn A, Furtado RHM, Kuder J, Murphy SA, Bhatt DL, Leiter LA, McGuire DK, Wilding JPH, Bonaca MP, Ruff CT, Desai AS, Goto S, Johansson PA, Gause-Nilsson I, Johanson P, Langkilde AM, Raz I, Sabatine MS, Wiviott SD (2019) Effect of dapagliflozin on heart failure and mortality in type 2 diabetes mellitus. Circulation 139(22):2528-2536. https://doi.org/10. 1161/circulationaha.119.040130

96. Fitchett D, Zinman B, Wanner C, Lachin JM, Hantel S, Salsali A, Johansen OE, Woerle HJ, Broedl UC, Inzucchi SE, investigators E-ROt (2016) Heart failure outcomes with empagliflozin in 
patients with type 2 diabetes at high cardiovascular risk: results of the EMPA-REG OUTCOME(R) trial. Eur Heart J 37(19):15261534. https://doi.org/10.1093/eurheartj/ehv728

97. Psaty BM, Lumley T, Furberg CD, Schellenbaum G, Pahor M, Alderman MH, Weiss NS (2003) Health outcomes associated with various antihypertensive therapies used as first-line agents: a network meta-analysis. JAMA 289(19):2534-2544. https://doi.org/ 10.1001/jama.289.19.2534

98. Staels B (2017) Cardiovascular protection by sodium glucose cotransporter 2 inhibitors: potential mechanisms. Am J Med 130(6S):S30-S39. https://doi.org/10.1016/j.amjmed.2017.04.009

99. Marti CN, Gheorghiade M, Kalogeropoulos AP, Georgiopoulou VV, Quyyumi AA, Butler J (2012) Endothelial dysfunction, arterial stiffness, and heart failure. J Am Coll Cardiol 60(16):14551469. https://doi.org/10.1016/j.jacc.2011.11.082

100. Zheng SL, Roddick AJ, Aghar-Jaffar R, Shun-Shin MJ, Francis D, Oliver N, Meeran K (2018) Association between use of sodiumglucose cotransporter 2 inhibitors, glucagon-like peptide 1 agonists, and dipeptidyl peptidase 4 inhibitors with all-cause mortality in patients with type 2 diabetes: a systematic review and metaanalysis. JAMA 319(15):1580-1591. https://doi.org/10.1001/ jama.2018.3024
101. Yang DY, He X, Liang HW, Zhang SZ, Zhong XB, Luo CF, Du ZM, He JG, Zhuang XD, Liao XX (2019) Comparative outcomes of heart failure among existent classes of anti-diabetic agents: a network meta-analysis of 171,253 participants from 91 randomized controlled trials. Cardiovasc Diabetol 18(1):47. https://doi. org/10.1186/s12933-019-0853-x

102. McMurray JJV, Solomon SD, Inzucchi SE, Kober L, Kosiborod MN, Martinez FA, Ponikowski P, Sabatine MS, Anand IS, Belohlavek J, Bohm M, Chiang CE, Chopra VK, de Boer RA, Desai AS, Diez M, Drozdz J, Dukat A, Ge J, Howlett JG, Katova T, Kitakaze M, Ljungman CEA, Merkely B, Nicolau JC, O'Meara E, Petrie MC, Vinh PN, Schou M, Tereshchenko S, Verma S, Held C, DeMets DL, Docherty KF, Jhund PS, Bengtsson O, Sjostrand M, Langkilde AM, Committees D-HT, Investigators (2019) Dapagliflozin in patients with heart failure and reduced ejection fraction. N Engl J Med. https://doi.org/10.1056/NEJMoa1911303

Publisher's note Springer Nature remains neutral with regard to jurisdictional claims in published maps and institutional affiliations. 